\title{
Compressive Strength Properties of Natural Gas Hydrate Pellet by Continuous Extrusion from a Twin-Roll System
}

\author{
Yun-Hoo Lee, Bong-Hwan Koh, Heung Soo Kim, and Myung Ho Song \\ Department of Mechanical, Robotics and Energy Engineering, Dongguk University-Seoul, \\ 30 Pildong-ro, 1-gil, Jung-gu, Seoul 100-715, Republic of Korea \\ Correspondence should be addressed to Bong-Hwan Koh; bkoh@dongguk.edu
}

Received 25 June 2013; Accepted 28 November 2013

Academic Editor: Mohd Sapuan Salit

Copyright (C) 2013 Yun-Hoo Lee et al. This is an open access article distributed under the Creative Commons Attribution License, which permits unrestricted use, distribution, and reproduction in any medium, provided the original work is properly cited.

This study investigates the compressive strength of natural gas hydrate (NGH) pellet strip extruded from die holes of a twin-roll press for continuous pelletizing (TPCP). The lab-scale TPCP was newly developed, where NGH powder was continuously fed and extruded into strip-type pellet between twin rolls. The system was specifically designed for future expansion towards mass production of solid form NGH. It is shown that the compressive strength of NGH pellet strip heavily depends on parameters in the extrusion process, such as feeding pressure, pressure ratio, and rotational speed. The mechanism of TPCP, along with the compressive strength and density of pellets, is discussed in terms of its feasibility for producing NGH pellets in the future.

\section{Introduction}

Natural gas hydrate (NGH), widely known for its selfpreservation effect [1], remains in a metastable state or quasiequilibrium under atmospheric pressure and subzero temperature (below $-20^{\circ} \mathrm{C}$ ). This property provides a solid background for the massive-scale exploitation of NGH and the development of pertinent technologies in storage, handling, and transportation. In this context, some of the economic benefits from the exploitation of NGH over conventional liquefied natural gas (LNG) have aroused significant global attention in recent years. Because NGH conveniently captures gases up to 170 times the amount of its own volume, the storage capacity per unit volume of pellet-type hydrate turns out to be much higher than that of compressed natural gas (CNG) [2-4]. Therefore, transporting natural gas in the form of NGH pellets has a robust benefit over LNG, in terms of price and reliability. The technology related to gas-to-solid (GTS) transition, for transporting natural gas produced from stranded small gas wells in the form of hydrate, becomes a promising alternative for conventional LNG transportation systems $[5,6]$. However, if the methane concentration is not rich enough, the self-preservation effect of NGH pellet may disappear. Thus, methane must be firmly trapped inside of the NGH pellet as a surrounding gas, if the pellet needs to be transported for prolonged time [7]. In order to fully exploit the advantage of the self-preservation effect, the technology related to GTS and pelletizing NGH becomes a critical research issue for many of the natural gas industries. Considering the massive scale of gas transportation, the extrusiontype method is the most effective for the continuous production of NGH pellets. Accordingly, to tackle the issue of NGH mass production, laboratory-scale continuous pelletizer for pilot-plants has been developed and discussed by numerous researchers in recent years [8].

In a previous study, Choi and Koh reported that the strength of ice pellet was dependent on the compressive pressure [9]. They developed capsule and cylinder shape vertical pelletizer, to investigate the effect of compressive pressure on the strength of ice pellet. Ko et al. and Shim also showed that the rotational speed and starting angle of pelletizer affect the physical properties of pellets [10, 11]. Also, Jung et al. recently investigated a hopper system of ball-type NGH pellets using the response surface method, to find an optimal design condition for hopper discharge [12]. Therefore, the strength of NGH pellet depends on the design parameters of the pelletizer, such as the size and surface friction of the disk, feeder mechanism, temperature conditions, and rotational speed. The study of these design parameters is a key issue for 


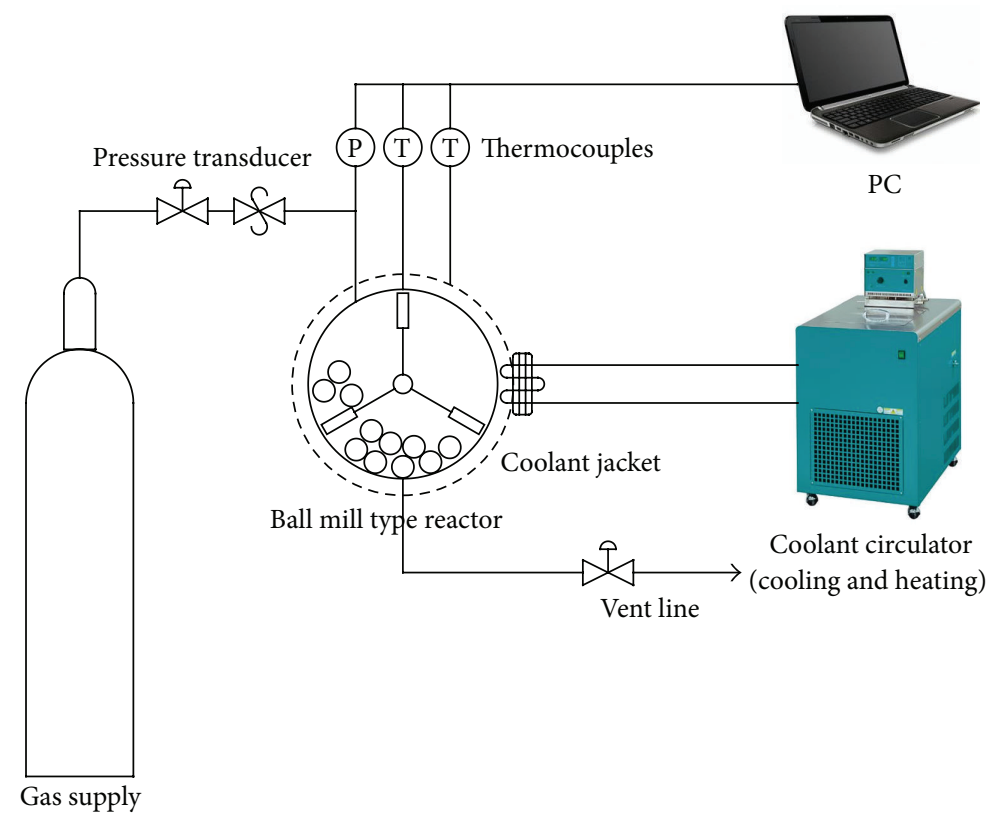

FIGURE 1: Schematic diagram of the production of NGH.

the development of the mass production of $\mathrm{NGH}$ pellet and the solid transport system of natural gas.

In this paper, we developed an extrusion-type twin-roll Press for continuous pelletizing system or TPCP, which is specifically designed for continuous production of NGH pellet. The TPCP is a laboratory-scale NGH pelletizing device. It is a gear-type system with two adjacent rolls, which push together and extrude hydrate powder through the outlet hole. The rotating twin-roll and overhead feeding weight create enough squeezing pressure to form hydrate pellet. The feeding hydrate powder was compounded through the lab-scale $\mathrm{NGH}$ reactor in advance. Particles of powder having diameter less than $1 \mathrm{~mm}$ were continuously fed into the pelletizing system. By using TPCP, we successfully extruded a long and thin rod-shaped NGH pellet. Also, we are able to measure the compressive strength of natural gas hydrate pellet according to the basic design parameters of pelletizer, such as feeder pressure, rotational speed of the disk, and starting angle of the pelletizer. Experimental results show that the mechanical strength of NGH pellet extruded by the TPCP system mainly depends on the rotational speed of the twin roll and overhead feeder pressure. This investigation result can be used as a background data for designing a mass production system of NGH pellet and loading/unloading mechanism for $\mathrm{NGH}$ ships in the near future.

\section{Experiment}

2.1. Hydrate Formation. In order to fabricate NGH pellets through the TPCP system, the feeding material or $\mathrm{NGH}$ powder compound needs to be formed through hydrate reactor. Figure 1 shows the schematics and process diagram of a laboratory-scale hydrate forming reactor. In order to meet the hydrate forming condition, a constant temperature bath was controlled to sustain a temperature level of $-0.5^{\circ} \mathrm{C}$. Also, $15 \%$ of ethylene glycol was added to the cooling water to prevent freezing, and coolant was circulated around the outer surface of the reactor. Before forming the hydrate powder compound, methane gas was filled up to 120 bar at the accumulator along with $2 \mathrm{~kg}$ water, and dozens of heavy stainless balls were added in the reactor. To remove the air in the reactor, methane gas was pressured up to 3 bar in the reactor, and the pressure was reduced down to atmospheric pressure through the vent line. This process was repeated three times, to completely remove air in the reactor. After air was removed, the reactor was pressured with methane gas up to 60 bar in the accumulator. Then, a motor-driven impeller was rotated to stir the methane gas, water, and stainless balls. During the process, constant-pressured methane gas was supplied to the reactor through a pneumatic regulator operated by a flow management program, and the pressure in the reactor was kept up to 60 bar. After 80 minutes, the hydrate powder was being formed in the reactor, and we could extract the powder at the constant temperature room, where the temperature was kept as low as $-20^{\circ} \mathrm{C}$. In the meantime, the conversion rate of the formed hydrate powder was measured. If the conversion rate reached over $60 \%$, then the hydrate powder was ready to be inserted into the TPCP for NGH pelletizing.

2.2. Hydrate Pellet Extrusion. In the process of pelletizing through the TPCP system, three major design parameters that might affect the mechanical strength of the NGH pellets after production were considered in this study. They were the pressure ratio $(\mathrm{PR})$, feeding pressure $(\mathrm{FP})$, and rotational speed of the twin roll (RPM). We investigated the influence of those three design parameters using two different conditions, respectively. Here, the pressure ratio is defined as the ratio of the output area to the input area of the feeder and is 


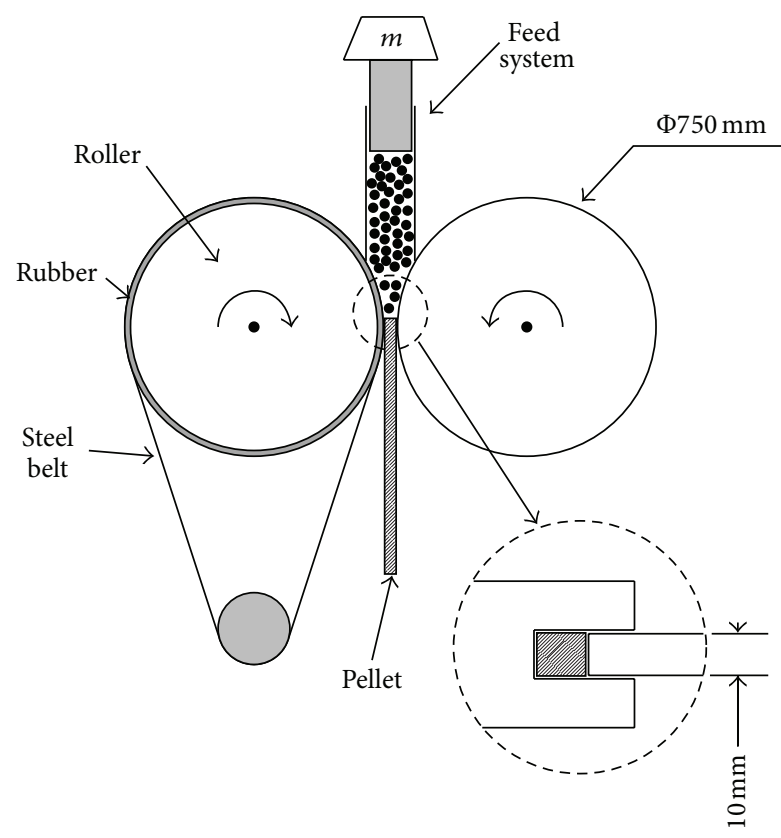

FIGURE 2: Schematics of the twin-roll press machine for continuous pelletizing.

TABLE 1: Case of pelletizing using TPCP.

\begin{tabular}{lcccccccc}
\hline Case & 1 & 2 & 3 & 4 & 5 & 6 & 7 & 8 \\
\hline PR & $1: 2$ & $1: 2$ & $1: 2$ & $1: 2$ & $1: 3$ & $1: 3$ & $1: 3$ & $1: 3$ \\
FP & $2.5 \mathrm{kgf}$ & $5 \mathrm{kgf}$ & $2.5 \mathrm{kgf}$ & $5 \mathrm{kgf}$ & $2.5 \mathrm{kgf}$ & $5 \mathrm{kgf}$ & $2.5 \mathrm{kgf}$ & $5 \mathrm{kgf}$ \\
RPM & 1 & 1 & 2 & 2 & 1 & 1 & 2 & 2 \\
\hline
\end{tabular}

directly related to the level of the feeding quantity of hydrate powder to the TPCP. Also, the feeding pressure can be simply expressed by the vertical weight applied to the top of the feeder. The FP basically indicates the amount of force for pushing the powder into the TPCP. From the preparatory experiments, two experimental conditions for each PR, FR, and RPM are determined. All the experimental conditions, that is, eight cases of different design parameters, are depicted in Table 1.

Figure 2 presents the schematics of the proposed twinroll press for the continuous pelletizing (TPCP) system. It appears that the productivity of the NGH pellet depends on the size of the die hole and the rotational speed of the twin rolls. The diameter of each disk of the twin roll was $750 \mathrm{~mm}$, and the width was $10 \mathrm{~mm}$. The distance between two rollers was fixed as $10 \mathrm{~mm}$. The pellet strip of NGH extruded from the TPCP was cut into rectangular parallelepipeds of $10 \mathrm{~mm} \times$ $10 \mathrm{~mm} \times 11 \mathrm{~mm}$ dimensions. The NGH pellet strips were used for the compressive strength test. For each case in Table 1, ten specimens were equally prepared for the test. Note that all the aforementioned processes were conducted inside the $-20^{\circ} \mathrm{C}$ freezer, to prevent dissociation of the NGH. Figure 3 illustrates the laboratory-scale twin-roll press machine for the continuous pelletizing system in the temperature-controlled chamber.

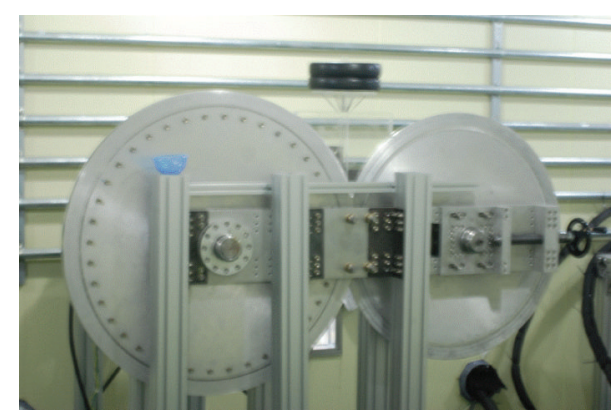

FIGURE 3: The lab-scale twin-roll press machine for continuous pelletizing.

2.3. Compressive Test of the Hydrate Pellet. In order to assess the mechanical strength of the NGH pellets, a compressive test was conducted using a universal test machine (UTM). The UTM has an environmental chamber that can control the test temperature, ranging from $-40^{\circ} \mathrm{C}$ up to $100^{\circ} \mathrm{C}$. In this study, all the compressive tests were conducted at temperature below $-25^{\circ} \mathrm{C}$. The NGH pellet specimen was placed between two horizontal disks and then slowly pressed by motor-driven UTM, until it developed cracks and eventually collapsed. The load cell on the bottom plate disk recorded the compressive load versus displacement data, to evaluate the compressive strength of each test specimen. Figure 4 illustrates the settings of the compressive test apparatus.

\section{Results and Discussion}

Mechanical properties, particularly the compressive strength of the NGH pellet, become some of the most important data, in designing the transportation system of solid-form natural gas. Here, the compressive strengths of NGH pellets under different pelletizing conditions of TPCP system were investigated; two PRs were $1: 2$ and $1: 3$, two FPs were $2.5 \mathrm{kgf}$, and $5 \mathrm{kgf}$, two RPMs were $1 \mathrm{rpm}$ and $2 \mathrm{rpm}$, respectively. Note that each of three design parameters having two conditions generates in total eight different extrusion conditions for NGH pellet production, as shown in Table 1.

The load-displacement curve of NGH pellet shows the typical pattern of elastoplastic response. Figure 5 shows a load-displacement curve of NGH pellet extruded from TPCP under the test condition of case 6 (PR 1:3, FP $5 \mathrm{kgf}$, and RPM $1)$. The curve depicts two moduli, that is, elastic $\left(E_{e}\right)$ and plastic modulus $\left(E_{p}\right)$. In this curve, the compressive strength of the NGH pellet is defined as the intersecting point of the linear curve fitting line before and after the occurrence of the yielding phenomenon. Note that the compressive strength is defined as a yielding load. The slope of the linear curve fitting line before the yielding point becomes the compressive stiffness of the NGH pellet.

Figure 6 illustrates the load-displacement curves of NGH pellet specimens fabricated under the conditions of cases 1 , 2,3 , and 4 . In test case 1 through 4 , all pressure ratios were fixed to $1: 2$, but feeding pressure and rotational speed were different for each case. The compressive strength and stiffness of the hydrate pellets were enhanced as the feeding pressure 
TABLE 2: Average yielding load and stiffness of NGH pellets.

\begin{tabular}{|c|c|c|c|c|c|c|c|c|}
\hline \multicolumn{9}{|c|}{ Unit: yielding load $(\mathrm{N})$, stiffness $(\mathrm{N} / \mathrm{mm})$} \\
\hline Case & 1 & 2 & 3 & 4 & 5 & 6 & 7 & 8 \\
\hline Yielding load & 341.2 & 545.5 & 488.2 & 752.9 & 168.9 & 294.3 & 439.9 & 495.5 \\
\hline Stiffness & 1578.5 & 1640.5 & 2793.3 & 3121.3 & 998.3 & 1543.3 & 1587.8 & 1891.5 \\
\hline
\end{tabular}

TABLE 3: Mass densities of NGH specimens.

\begin{tabular}{lcccccccc}
\hline & & \multicolumn{3}{c}{ Unit: $\mathrm{kg} / \mathrm{m}^{3}$} & & & \\
Case & 1 & 2 & 3 & 4 & 5 & 6 & 7 \\
\hline Mass density & 697.7 & 750.0 & 706.8 & 804.6 & 686.4 & 720.5 & 777.3 & 786.4 \\
\hline
\end{tabular}

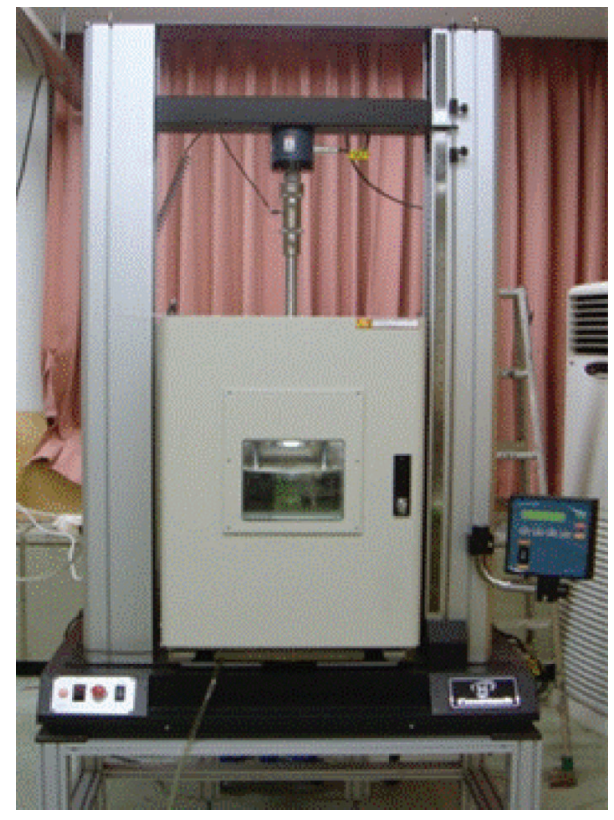

(a) UTM with temperature controllable chamber

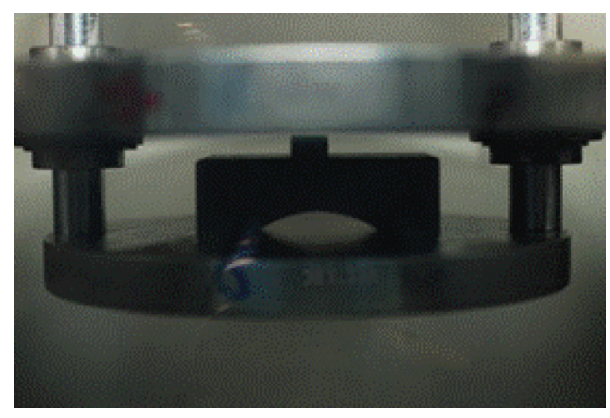

(b) Layout of compressive test specimen

FIGURE 4: Compressive strength test of NGH pellet specimen in UTM.

and rotational speed increased. Ten specimens were tested for each case, and average values of compressive strength and stiffness are summarized in Table 2. For case 1 and case 2 , hydrate pellets were extruded under the same pressure ratio $(1: 2)$ and rotational speed (1 rpm), but different feeding pressure. The yielding loads of hydrate pellets were $341.2 \mathrm{~N}$

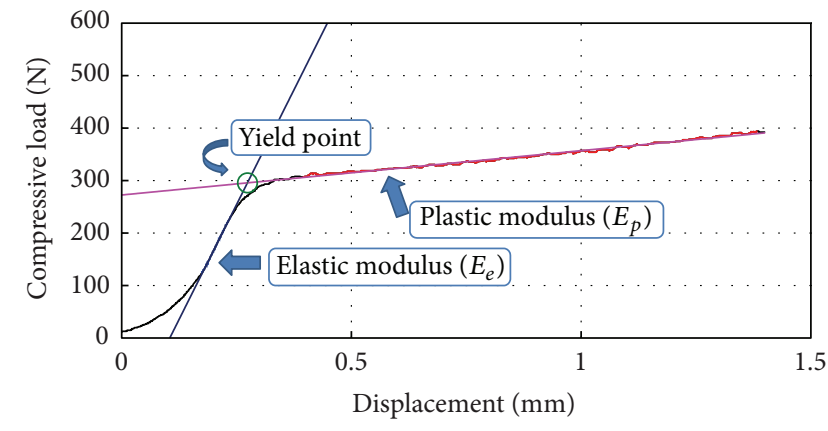

FIGURE 5: Load-displacement curve of NGH pellet (PR 1:3, FP 5 kgf, RPM 1).

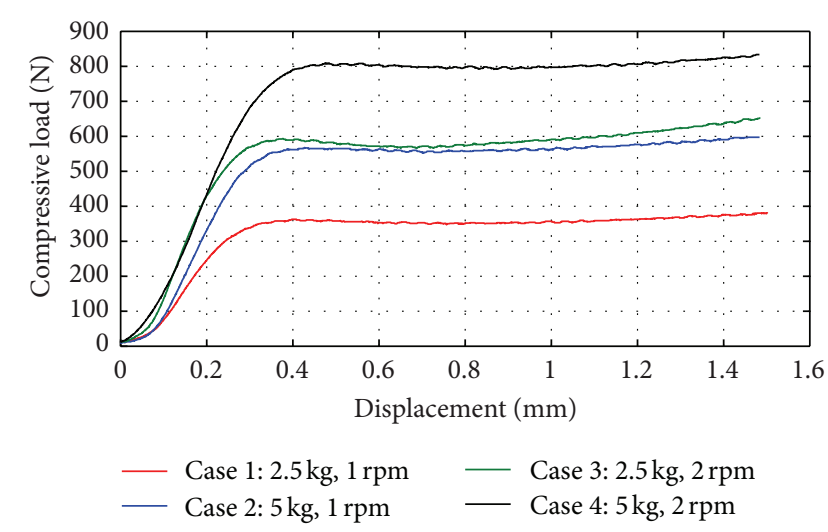

FIGURE 6: Load-displacement curve of NGH pellet (cases 1, 2, 3, and 4).

and $545.5 \mathrm{~N}$ for cases 1 and 2 , respectively. In this case, the yielding load of NGH pellet increased up to $59.9 \%$ as the feeding pressure doubled. Cases 3 and 4 exhibited similar trends, and yielding load increased $54.2 \%$. It is observed that the yielding load of NGH pellet extruded under the same condition of pressure ratio and rotational speed was enhanced, as the feeding pressure increased. From another point of view, cases 1 and 3 provided the same pressure ratio and feeding pressure condition, but different rotational speed of the TPCP system. In this case, the yielding load of NGH pellet increased $43.1 \%$ from case 1 through 3 , which represents that yielding loads were proportional to the rotational speeds. 


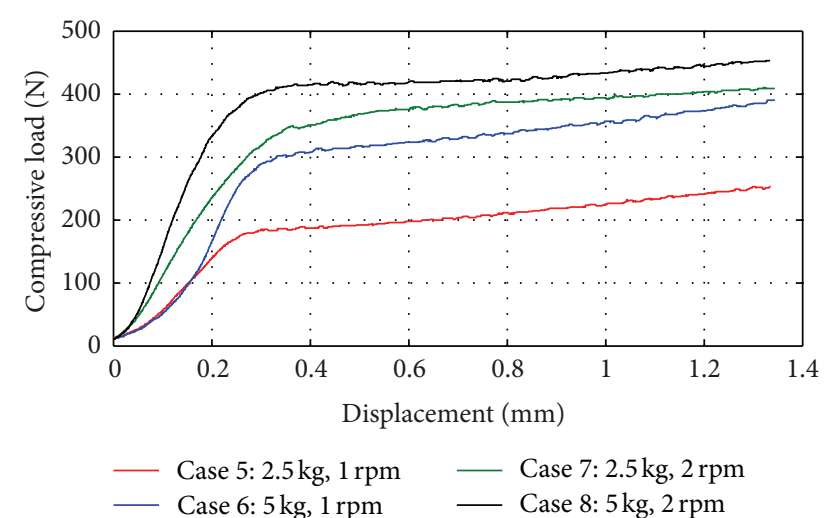

Figure 7: Load-displacement curve of NGH pellet (cases 5, 6, 7, and 8).

The same phenomenon was observed when we examined cases 2 and 4 . The experimental result shows that the yielding load of NGH pellets was proportional to the feeding pressure and rotational speed, under the constant pressure condition. Therefore, case 4 provided the largest yielding load among the four different cases. Also, the stiffness of NGH pellet showed the same trend.

Figure 7 illustrates the load-displacement curves of NGH pellets fabricated under the conditions of cases $5,6,7$, and 8 . In cases 5 through 8 , the pressure ratio was fixed to $1: 3$, but feeding pressure and rotational speed were different for each case. For cases 5 and 6 , NGH pellets were extruded under the same pressure ratio $(1: 3)$ and rotational speed $(1 \mathrm{rpm})$, but different feeding pressure. The yielding loads of hydrate pellets were $168.9 \mathrm{~N}$ and $294.3 \mathrm{~N}$ for cases 5 and 6 , respectively. Here, the yielding load of $\mathrm{NGH}$ pellet increased up to $74.2 \%$, if the feeding pressure was doubled. Cases 7 and 8 provide the same trend, and the yielding load increased $4.5 \%$. It is also noticed that the yielding load of NGH pellet extruded under the same pressure ratio and rotational speed improved, as the feeding pressure increased, for the pressure ratio of $1: 3$. In the sense of rotational speed of cases 5 through 8 , the yielding load increased proportional to the rotational speed, which was observed in cases 1 through 4 . The only different test parameter between cases $1 \sim 4$ and cases $5 \sim 8$ was pressure ratio. The yielding load and stiffness of NGH pellet for relatively low pressure ratio $(1: 2)$ were higher than those of high pressure ratio $(1: 3)$ conditions. The pressure ratio has a strong relationship to the amount of feeding NGH powder. Therefore, it is concluded that the higher the pressure ratio condition feed, the less the amount of NGH powder to the die hole, which results in the lowered yielding load. The yielding load and stiffness of hydrate pellets extruded under the eight different conditions are summarized in Figure 8. The yielding load and stiffness of hydrate pellet were enhanced as the feeding pressure and rotational speed increased. The same effect also occurred as the pressure ratio decreased.

The yielding load and stiffness of NGH pellet are closely related to its mass density. The mass densities of NGH pellets extruded under the eight different conditions are listed in Table 3. The trend of mass density shows a similar pattern to the yielding load and stiffness. From these observations,

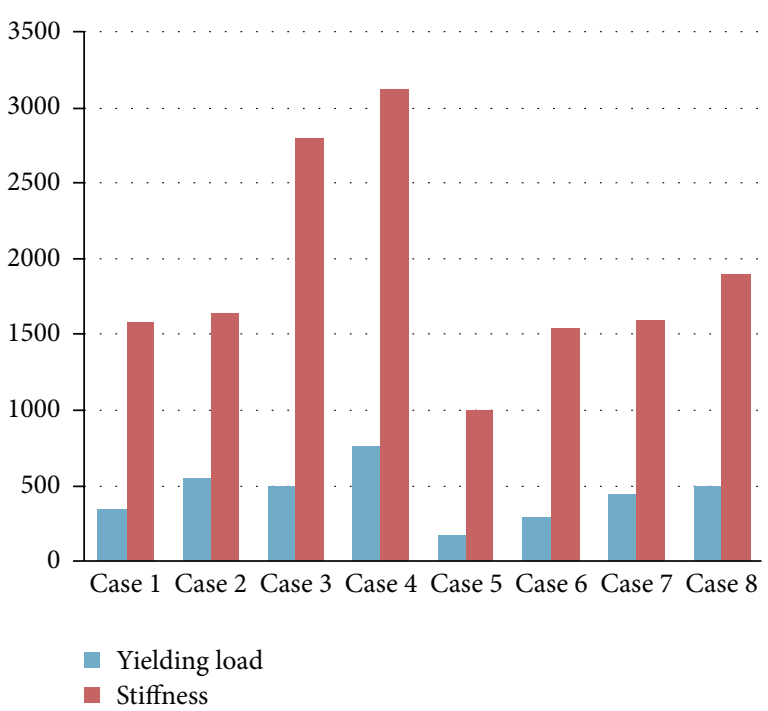

FIGURE 8: Yielding load and stiffness of NGH pellet.

the best condition for the largest yielding load and stiffness of hydrate pellet is case 4 , which has a feeding pressure of $5 \mathrm{kgf}$, rotational speed of $2 \mathrm{rpm}$, and pressure ratio of $1: 2$. It is also concluded that the compressive strength of the NGH pellet is significantly affected by the feeding pressure, rotational speed, and pressure ratio, which constitute fundamental design conditions for the mass-production system of $\mathrm{NGH}$ pellets.

\section{Conclusions}

In this study, the compressive strength of $\mathrm{NGH}$ pellet extruded by a twin-roll press for continuous pelletizing system is investigated. The NGH powder was first produced by a laboratory-scale hydrate reactor. NGH pellet strip was continuously extruded by the newly developed TPCP system. The feeding pressure, rotational speed, and pressure ratio were considered as the primary test conditions for making NGH pellet. Two different feeding pressures, rotational speeds, and pressure ratios were investigated, and hydrate pellets were extruded, according to eight different fabrication conditions. The yielding load, stiffness, and mass density of hydrate pellets were highly affected by these three design parameters, and they increased, as the feeding pressure and rotational speed increased. The same effect could also be achieved by decreasing the pressure ratio. Maximum yielding load and stiffness are $752.9 \mathrm{~N}$ and $3121.3 \mathrm{~N} / \mathrm{mm}$ at PR $1: 2$, FP $5 \mathrm{kgf}$, and $2 \mathrm{rpm}$, respectively. These values are thought to be enough compressive strength for solid transportation of NGH. The experimental data could be used for solving the design problems of solid form of a gas or NGH pellet transporting system in the near future.

\section{Acknowledgment}

This work was supported by the Korea Research Foundation Grant funded by the Korean Government (MOEHRD) 
(2006RER03P010000), in which main calculations were performed by using the supercomputing resource of the Korea Institute of Science and Technology Information (KISTI).

\section{References}

[1] J. S. Gudmundsson, "Method for production of gas hydrates for transportation and storage," U.S. patent no. 5536893A, July 1996.

[2] S. H. Lee, Y. S. Yoon, and K. J. Seong, "Experimental study on the dissociation characteristics of methane hydrate pellet by hot water injection," Transactions of the Korean Society of Mechanical Engineers, B, vol. 35, no. 11, pp. 1177-1184, 2011.

[3] S. Watanabe, S. Takahashi, and H. Mizubayashi, "A demonstration project of NGH land transportation system," in Proceedings of the 4th International Conference on Gas Hydrates, Yocohama, Japan, May 2008.

[4] D. W. Davidson, S. K. Garg, S. R. Gough et al., "Laboratory analysis of a naturally occurring gas hydrate from sediment of the Gulf of Mexico," Geochimica et Cosmochimica Acta, vol. 50, no. 4, pp. 619-623, 1986.

[5] J. S. Gudmundsson and O. F. Graff, "Hydrate non-pipeline technology for transport of natural gas," in Proceedings of the 22nd World Gas Conference, 2003.

[6] H. Kanda, "Economic study on natural gas transportation with natural gas hydrate (NGH) pellets," in Proceedings of the $23 \mathrm{rd}$ World Gas Conference, pp. 1990-2000, June 2006.

[7] H. J. Hong and M. H. Song, "Decomposition characteristics of methane hydrate powder during decompression," in Proceedings of KSME Annual Conference, pp. 13-17, Seoul, Republic of Korea, January 2010.

[8] T. Iwasaki, Y. Katoh, S. Nagamori, S. Takahashi, and N. Oya, "Continuous natural gas hydrate pellet production (NGHP) by process development unit (PDU)," in Proceedings of the 5th International Conference on Gas Hydrates, 2005.

[9] J.-H. Choi and B.-H. Koh, "Compressive strength of ice-powder pellets as portable media of gas hydrate," International Journal of Precision Engineering and Manufacturing, vol. 10, no. 5, pp. 85-88, 2009.

[10] T. J. Ko, J. H. Kim, and I. J. Yoon, "A study of WC end-milling manufacturing and cutting ability evaluation by using powder injection molding," International Journal of Precision Engineering and Manufacturing, vol. 10, no. 4, pp. 13-17, 2009.

[11] H. B. Shim, "Improving formability to develop miniature stamping technologies," International Journal of Precision Engineering and Manufacturing, vol. 10, no. 2, pp. 117-125, 2009.

[12] U. Jung, J. H. An, B. S. Lim, and B. H. Koh, "Modeling discharge of pellets from a hopper using response surface methodology," International Journal of Precision Engineering and Manufacturing, vol. 13, no. 4, pp. 565-571, 2012. 

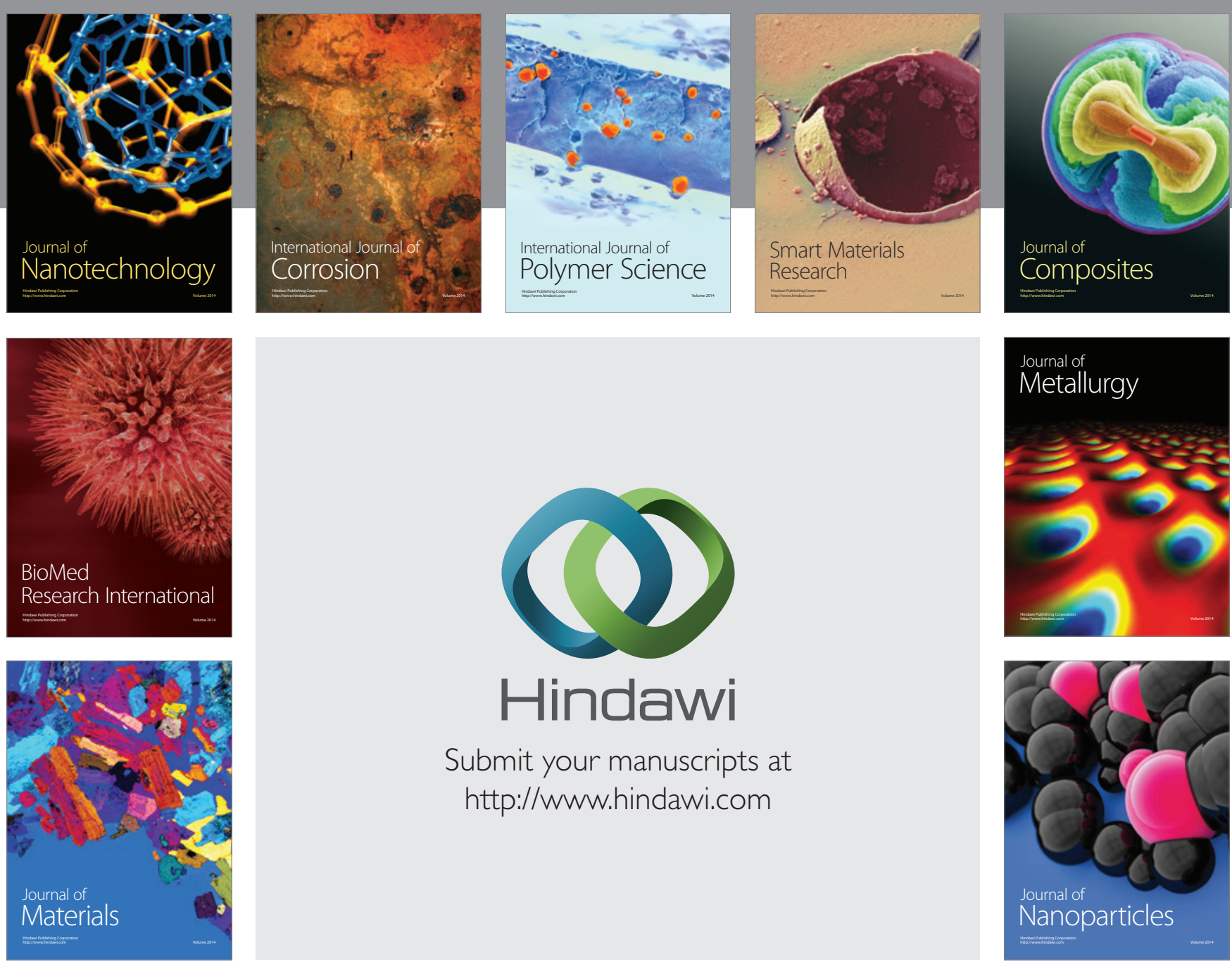

Submit your manuscripts at http://www.hindawi.com
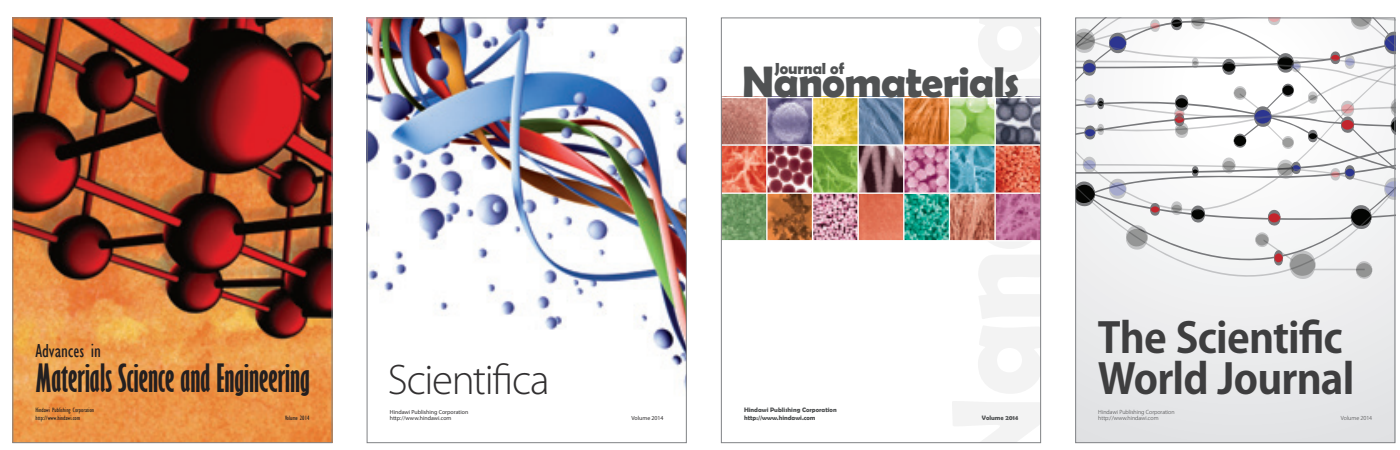

\section{The Scientific World Journal}
